Pre-print version of the paper accepted for publication in Synthese

\title{
Knowledge How, Ability, and the Type-Token Distinction
}

\section{Garry Young}

\begin{abstract}
This paper examines the relationship between knowing how to $G$ and the ability to $G$, which is typically presented in one of the following ways: (a) knowing how to G entails the ability to G; (b) knowing how to $\mathrm{G}$ does not entail the ability to $\mathrm{G}$. In an attempt to reconcile these two putatively opposing positions, I distinguish between type and token actions. It is my contention that $\mathrm{S}$ can

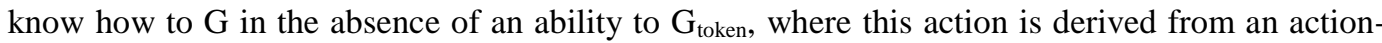
type, but not in the absence of the ability to perform the action-type itself $\left(\mathrm{G}_{\mathrm{type}}\right)$. This refinement is an attempt to reconcile differences between intellectualism and anti-intellectualism (broadly construed) with regard to knowledge how and ability.
\end{abstract}

Keywords: Intellectualism; Knowing how; Knowing that; Ability entailment; Actiontype, action-token; Epistemic reduction

\section{Introduction: A question of ability}

When considering the entailment between knowledge how and ability, logic dictates one of two possibilities: 
i. Knowing how to $\mathrm{G}$ entails the ability to $\mathrm{G}$

ii. Knowing how to $\mathrm{G}$ does not entail the ability to $\mathrm{G}^{1}$

Broadly construed, (ii) is a feature of intellectualism with regard to knowledge how and (i) is characteristically anti-intellectualist. ${ }^{2}$ Things are, however, a little more complicated than this. Whether an entailment is said to exist between knowing how and ability has typically depended on what is meant by knowledge how. Fridland (2013), for example, distinguishes between knowledge how and knowledge-about-how: the former referring to knowledge-in-action, which identifies knowledge as embodied and situated (Noë, 2005) and the latter about the way an action is performed (knowing what is involved in performing $\mathrm{G}$, or how one Gs). ${ }^{3}$ I shall adopt the terms 'knowledge-abouthow' and 'knowledge-in-action', here. The latter I intend to identify with intelligent action.

In line with the relationship espoused in (ii), a common way to show the lack of entailment between knowledge how and ability takes the following form: It is perfectly possible when trying to perform some task - a magic trick, say - that $S$ will lack the ability to perform $\mathrm{G}$ (the magic trick), owing to a lack of dexterity in the fingers, but nevertheless know how $\mathrm{G}$ is performed (that is, know how one Gs). Here, S's know-

\footnotetext{
${ }^{1}$ Snowdon (2003, p.2) uses the term "Capacity Thesis" when discussing a possible entailment between knowledge how and ability. The Capacity Thesis states: Knowing how to $\mathrm{G}$ does in fact consist in being able to $G$, in having the capacity to $G$. Knowing how ascriptions ascribe abilities or capacities to do the mentioned action. Statement (i) would therefore support the Capacity Thesis; statement (ii) would oppose it.

${ }^{2}$ Intellectualism (broadly construed) is the view that knowledge how is dependent on, insofar as it is reducible to, knowledge that (or propositions). Anti-intellectualism (again, broadly construed) is the view that knowledge how and knowledge that are independent. Each constitutes a different species of knowledge such that the former is not reducible to the latter.

${ }^{3}$ See Fantl (2008) for a detailed discussion on varieties of knowledge how.
} 
how, I take to be referring to 'knowledge-about-how'. Moreover, saying that $\mathrm{S}$ knows how to $\mathrm{G}$ is equivalent to bestowing on $\mathrm{S}$ propositional knowledge such that $\mathrm{S}$, in knowing how $\mathrm{G}$ is performed, knows that $\mathrm{G}$ involves doing $x, y, z$. Snowdon (2003), in line with Stanley and Williamson (2001), and in keeping with intellectualism generally, refers to the reducibility of knowledge how to propositions in the manner described as the standard treatment, proffering the following argument in support of this epistemic reduction. Often we will ascribe to someone knowledge of why something is the case, or of knowing when or where something is, or whether or to whom it belongs. Each knowledge- $w h$ constitutes a different knowledge relation; yet each is ultimately a form of knowledge that is susceptible to the same standard treatment. ${ }^{4}$ Thus, the argument goes, knowing when $x$ will occur amounts to nothing more than knowing that $x$ will take place at a particular time. So it is with knowing how. Knowing how to escape from the locked cage is simply a case of knowing that one must do such and such, and in this rather than that order.

I accept the standard treatment of knowledge how (qua knowledge-about-how) and its epistemic reduction to propositional knowledge. Nevertheless, I intend to demonstrate that knowledge-about-how, as illustrated by the magic trick example without wishing to appear disingenuous -entails a much more abstracted ability than the personal ability shown to be redundant in this example. This I refer to as the abstracted ability entailment (see Section 2). Moreover, at the risk of overemphasizing what might be regarded as a trivial truth, I consider the necessity of this abstracted ability to be true for both definitions of knowledge how. Somewhat more importantly, though, I will argue that knowledge how (qua knowledge-in-action), at the personal level - that is,

\footnotetext{
${ }^{4}$ See, however, Bengson \& Moffett (2012) and Devitt (2011) for challenges to the legitimacy of this claim.
} 
with regard to S's own knowledge how and ability - both does and does not entail personal ability. To avoid this prima facie contradiction, I distinguish between type and token actions. Thus, S knowing how to G (qua knowledge-in-action) entails the ability to G-type but not G-token (see Section 4). By stipulating what a lack of ability (to G) does and does not involve, I am able to reconcile the view that $\mathrm{S}$ can know how to $\mathrm{G}$ (qua knowledge-in-action) without the ability to $\mathrm{G}$ with the claim that ability is required. Unfortunately, distinguishing between type and token action, in addition to clarifying the nature of S's ability with regard to performing G (qua an action-token derived from an action-type), raises the possibility that $\mathrm{S}$ could claim knowledge of how to do something (a particular action-token) that potentially cannot be done. A response to this possibility is presented (see Section 5), followed by a conclusion in which I state that intellectualism and anti-intellectualism with regard to knowledge how can be reconciled, at least in terms of the entailment between knowing how to $G$ and one's personal ability to $\mathrm{G}$, if one distinguishes between type and token actions.

In the next section, I introduce the abstracted ability entailment, and show how it is necessary both for knowledge-about-how and knowledge-in-action. Such groundwork, although unremarkable, nevertheless prepares the way for the main argument to follow.

\section{Knowledge-about-how and the abstracted ability entailment}

Consider the following statement:

(1) S knows how to G 
Irrespective of which definition of knowledge how one is using, what does this statement tell us about G? It tells us that $\mathrm{G}$ is performable: for $\mathrm{S}$ (or anyone else) cannot know how to do something that cannot be done. By 'cannot be done' I mean cannot be done now or at any time in the future; nor was it ever possible to perform $G$ in the past. 'Cannot be done' must therefore be distinguished from 'has not been done': for even where $\mathrm{G}$ has not been done, it may still be do-able and therefore performable. As such:

(2) Knowing how to $G$ entails that $G$ is performable.

For $\mathrm{G}$ to be performable, there must be an occasion - call it $t_{1}-$ when the ability to $\mathrm{G}$ exists: that is, when someone is able to perform G. Therefore:

(3) G being performable entails that someone has the ability to perform G on some occasion $\left(\mathrm{t}_{1}\right)$

Although an occasion when someone has the ability to perform $G$ is necessary for $G$ to be performable, it is not sufficient for it to be performed. Someone may be able to perform $\mathrm{G}$ at $\mathrm{t}_{1}$ but the conditions that enable this ability to be expressed may not be present. ${ }^{5}$ Irrespective of these enabling conditions, for $\mathrm{G}$ to be performed, a necessary

\footnotetext{
${ }^{5}$ To borrow an example from Millikan (2000), let us allow that performance G equates to cooking dodo meat (the dodo is an extinct bird that is believed to have died out around 1681). At time $t_{0}$ (say, 1650), it
} 
condition is that the ability to $\mathrm{G}$ exists now (qua someone having the ability to perform the action). From this, we can accept the following conclusion:

(4) Performing $G$ entails the ability to $\mathrm{G}^{6}$

Taking stock, I have shown, by way of a set of entailments, that knowing how to G entails that $\mathrm{G}$ is performable, that $\mathrm{G}$ being performable entails that someone has the ability to perform $G$ on some occasion ( $\left.t_{1}\right)$, and that performing $G$ entails that the performer has the ability to $\mathrm{G}$. The abstracted ability entailment ( $\mathrm{AE}_{\text {abstracted }}$ ) therefore holds true:

AE abstracted: Knowing how to $G$ entails the ability to $G$

As already noted, at the personal level, $S$ could know how to perform $G$ (the magic trick) but not have the ability to perform it. Such a possibility is compatible with the more general requirement evident within the $\mathrm{AE}_{\text {abstracted. In relation to the ability }}$ entailment alone, all that is required for $S$ to know how to $G$ is for there to be an

was the case that people had the ability to cook dodo meat and the dodo bird existed (to be cooked). Given these enabling conditions, people were able to exercise their ability to cook dodo meat and so performance $\mathrm{G}$ could be, and was, performed. However, at time $\mathrm{t}_{1}$ (in 1700), several years after the dodo bird officially became extinct, it seems reasonable to surmise that people at this time also had the ability to cook dodo meat but, owing to the bird's extinction, were unable to exercise this ability. As a result, G could not be performed, but not owing to a lack of ability.

${ }^{6}$ I distinguish performing $G$ from $G$ happening. The latter could be attributed to chance (some freak occurrence), the former requires the intention to $G$ and for $G$ to be performed intentionally (see the Conditions for Intelligent Action, Section 3). 
occasion $\left(t_{1}\right)$ when someone has the ability to $G$, thus making $G$ performable. ${ }^{7}$ This, however, leaves open the possibility that $S$ could know how to $G$ (because $G$ is performable, given statement 3 ), on an occasion other than $t_{1}$ when the ability to $G$ does not exist (that is, when no one at that time possesses the ability to G). This is not to say that $\mathrm{S}$ can know how to do something that cannot be done; rather, it is to say simply that S could know how to do something which no one, presently, has the ability to do. Put differently, S (or anyone) could know how to G (qua knowledge-about-how) - and so know how one Gs - even though G cannot, at present, be performed owing to a global lack of ability.

We can see just such a possibility described in the example from Bengson and Moffett (2007) of Irina Slutskaya, an Olympic figure skater who, we are told, knows how to perform a quintuple salchow despite being unable to do so. What the case of Irina highlights, Bengson and Moffett tell us, is that "there is good reason to think that knowing how to do a quintuple salchow does not entail the ability to do one" (2007, p.34). Moreover, they accept that "basically all world class figure skaters know how to do a quintuple salchow, but owing to the athletic difficulty of the jump only a few (if any) of them can actually do one" (p.34).

In the context in which it occurs, Bengson and Moffett's claim - that knowing how to $\mathrm{G}$ does not entail the ability to $\mathrm{G}$ - is describing a lack of personal level entailment on the part of Irina (S, qua Irina, knowing how to $\mathrm{G}$ does not entail that $\mathrm{S}$, qua Irina, has the ability to G). What is not clear from Bengson and Moffett's

\footnotetext{
${ }^{7}$ To be clear, I am not saying that the abstracted ability entailment is sufficient for S to know how to G. It is perfectly possible and likely that there will be lots of people who do not know how to $G$ (whatever $G$ may be) even where the ability to $\mathrm{G}$ is ubiquitous. Instead, I am merely saying that, as far as ability's relationship to knowledge how (qua knowledge-about-how) is concerned, the abstracted ability entailment is sufficient to satisfy the entailment between knowledge how and ability.
} 
description, however, is whether some of the other world class figure skaters, in contrast to Irina, have the ability to $\mathrm{G}$ even though (let us allow) none has actually performed the manoeuvre. (I interpret the phrase "few (if any)" to mean that Bengson and Moffett are allowing the possibility that no one has yet performed the jump.)

If the $\mathrm{AE}_{\text {abstracted }}$ is to be satisfied, then statements (2) and (3) must likewise be satisfied (G must be performable, meaning someone must have the ability to $\mathrm{G}$ on some occasion, $t_{1}$ ). But statement (4), at least in my version of the vignette, has not been satisfied; meaning that $\mathrm{G}$ (the quintuple salchow) has not been performed by anyone. Where knowledge how equates to 'knowledge-about-how', this does not prevent Irina and all of the other world class figure skaters from knowing how to $G$ (that is, knowing how one Gs), as Bengson and Moffett declare. Indeed, it would make sense that knowledge how in this context is not only reducible, but has to be reducible, to propositions, just as the standard treatment attests: for how else could one express knowledge of a performance that entails only abtracted ability (and not personal ability) except through propositions (knowing that such and such must be done, etc.)?

The $\mathrm{AE}_{\mathrm{abstracted}}$ does seem vulnerable to the somewhat counter intuitive position regarding knowledge-about-how, though: that all world class figure skaters (including Irina) know how to perform a sextuple, septuple and octuple salchow, respectively (I will return to this point in Section 5 when discussing knowledge-in-action). To borrow from Bengson and Moffett, one could say: Basically all world class figure skaters know how to do a sextuple, septuple and octuple salchow, but owing to the athletic difficulty of the jump none of them can actually do one. Given this, how far should we stretch the knowledge claim? Should we permit Irina or any other world class skater to announce: 
"Yes, I know how to perform a chilialchow" (a salchow that involves 1,000 rotations through the air)?

What might Bengson and Moffett say in response? In anticipation, consider the following example:

Louis, a competent mathematician, knows how to find the $n^{\text {th }}$ numeral, for any numeral $n$, in the decimal expansion of $\pi$. He knows the algorithm and knows how to apply it in a given case. However, because of principled computational limitations, Louis (like all ordinary human beings) is unable to find the $10^{46}$ numeral in the decimal expansion of $\pi$. (2012, p.170)

Bengson and Moffett then go on to say that:

Louis cannot reasonably hope to succeed in finding the $10^{46}$ numeral in the decimal expansion of $\pi$ when he tries. His inability is pervasive. Yet he still knows how to find it. (ibid., p.171)

By the same token, Irina, or any other world class figure skater, cannot reasonably hope to succeed in performing the chilialchow; her inability is pervasive. In fact, everyone's inability is pervasive. Yet, following Bengson and Moffett example of Louis, is there not a sense in which Irina knows how to perform the manoeuvre, insofar as she knows how to perform a salchow and knows how to vary the number of rotations through the air which differentiates the different salchows? As such, does she not have a good 'grasp' of what a chilialchow entails. ${ }^{8}$

\footnotetext{
${ }^{8}$ It may be that the chilialchow (or even some of the other suggested salchows) requires drastic changes to how one approaches the manoeuvre which bears little relation to triple, quadruple or even quintuple salchows, and therefore entails a different ability to that required for these salchows.
} 


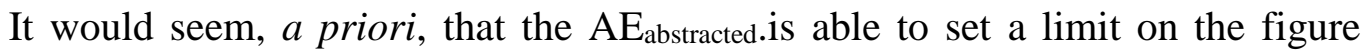
skaters' knowledge how (qua knowledge-about-how): namely, knowledge limited to that which is performable and therefore that for which someone has the ability to $\mathrm{G}$ on some occasion $\left(t_{1}\right)$. In practice, however, it is difficult to see how this could be implemented except in the more extreme cases, as the chilialchow example illustrates. In relation to a chilialchow, one may feel intuitively (and more than likely draw on evidence from human physiology to support one's intuition) that statements (2) and (3) are not met, and so one cannot know how to $\mathrm{G}$ in this case. But what about the sextuple, septuple and octuple salchows? Here, our intuition may fail us, insofar as it may be a less reliable indicator of what is performable and/or form less of a consensus with other people's intuitions in this regard. Moreover, our understanding of human physiology may be able to offer little that is definitive in terms of the performability (in principle) of each manoeuvre.

As mentioned, I will to return to the somewhat thorny issue of performability in the absence of current ability in Section 5 when discussing knowledge-in-action; only this time in relation to personal ability rather than abstracted ability. Until then, let us turn our attention to the nature of the entailment between knowledge-in-action and ability (Section 3), before discovering how distinguishing between type and token actions helps qualify this entailment (Section 4).

\section{Knowledge-in-action and the personal ability entailment}

To explore the entailment between knowledge-in-action and ability, I draw again from an example by Bengson and Moffett. This time, Bengson and Moffett (2012) ask us to 
consider Pat who, we are told, is an accomplished skier and in high demand as an instructor of complex ski stunts, despite the fact that he is unable to perform these stunts himself. ${ }^{9}$ According to the authors, "Pat knows how to do the stunts. But is not able, and has never been able, to do them" (2012, p.168). What Bengson and Moffett mean by the phrase "Pat knows how to do the stunts" is that he knows what is required for him to do the stunts, rather than the more general claim that he only knows what performing the stunts involves. To make clear what they mean by this, they contrast Pat's knowledge how with Albert's: a scientist who does not ski, yet studies the mechanics of skiing. Because of his theoretical expertise, we are told that Albert knows how the stunts are performed, and therefore how one does the stunts in terms of the underlying physiology of the movements. It is then contrived that Pat also has this knowledge. Having set the scene, Bengson and Moffett draw the following conclusion:

...Pat and Albert both know how one does the stunts; [yet] neither is able to do the stunts. But plainly a significant difference remains: only Pat knows how to do the stunts. Indeed, even though Pat cannot do them, he grasps the stunts in a way that Albert, who only knows the theory, does not. (2012, p.169; emphasis in original)

What are we to make of this example? Apparently - although we are told "plainly" - a significant difference exists between Pat and Albert's knowledge how, such that Pat grasps the stunts in a way that Albert does not. What is the epistemic nature of this grasping and what are we to conclude from this about the entailment between knowledge how and ability?

\footnotetext{
${ }^{9}$ See Stanley and Williamson (2001, p.416) for a similar example.
} 
Both Pat and Albert know how one does the stunts. Based on earlier discussion, this is equivalent to each having knowledge-about-how the ski stunts are performed. For this to be the case, in relation to the ability entailment, only $\mathrm{AE}_{\text {abstracted }}$ must be satisfied. Thus, the ski stunts must be performable, meaning there must be an occasion when someone has the ability to do the ski stunts. This being the case, neither Pat nor Albert need possess the ability to do the ski stunts in order to have knowledge how in the sense we are discussing here: namely, knowledge-about-how (so we can agree with Bengson and Moffett on this point). In addition, we are told that Pat knows what is required for him to do the stunts in a way that Albert does not. Before discussing this additional (and distinguishing) knowledge claim, what is interesting (and important) about Bengson and Moffett's example - even though the focus of their example concerns knowledge about ski stunts - is that Pat knows how to ski, whereas Albert does not. Pat, in performing $\mathrm{G}$ (skiing), must have the ability to ski (something of a trivial truth, perhaps, but one we can build on, and one I will support below in relation to intelligent action). Albert, on the other hand, does not need the ability to ski to satisfy his claim to knowledge (qua knowledge-about-how to ski).

We will return to the ski stunts in a moment. For now let us consider how Pat and Albert differ with regard to their ability to ski and their respective knowledge how. To understand this relationship, we first need to understand the relationship between knowledge-in-action and intelligent action. For this, we turn to Ryle.

If we allow that performing $\mathrm{G}$ entails performing intelligent action then what makes an action intelligent? In The Concept of Mind, Gilbert Ryle has the following comment to make about intelligent action: 
In judging that someone's performance is or is not intelligent, we have, as has been said, in a certain manner to look beyond the performance itself. For there is no particular overt or inner performance which could not have been accidently or 'mechanically' executed by an idiot, a sleepwalker, a man in a panic... We observe, for example, a soldier scoring a bull's eye. Was it luck or was it skill? If he has the skill, then he can get on or near the bull's eye again, even if the wind strengthens, the range alters and the target moves... There is no one signal of a man's knowing how to shoot, but a modest assemblage of heterogeneous performances generally suffices to establish beyond reasonable doubt whether he knows how to shoot or not. (1949, pp.45-46)

In the extract above, Ryle equates an intelligent action (or performing an action intelligently) with knowledge how. If S performs G intelligently then S knows how to G. In Ryle's example, the intelligent performance being debated is that of shooting a rifle: let us call this action, G. It is important to be clear, however, that $\mathrm{G}$ (shooting a rifle) should not be taken to mean the same as firing a rifle (qua discharging a weapon): let us call this action, F. Implicit within performance $\mathrm{G}$ is the understanding that one is firing one's rifle at something and, further, that for this to be an intelligent performance one sets out with the intention of hitting what one is aiming at. Yet as Ryle points out, whether the soldier's performance was an example of $\mathrm{G}$ or $\mathrm{F}$ cannot be established through a measure of the particulars of the action itself at any given time, including a successful outcome. It may be that, by luck alone, the soldier in performing $\mathrm{F}$ happens to hit the bull's eye of the target in front of him in the absence of any prior intention. But even if one sets out with the intention of at least trying to hit what one is aiming at, for a claim to intelligent action and therefore knowledge of how to $\mathrm{G}$ (qua knowledgein-action), it is not enough that the novice soldier should (on his first attempt) point his rifle at the target, fire and hits the bull's eye. Conversely, it should not be said of the 
experienced soldier who fires and misses on a particular occasion that he no longer knows how to $\mathrm{G}$ or that this performance was unintelligent. In the same way that a case of good fortune should not find a place among any of the conditions for intelligent performance, so a case of misfortune should not be able to negate it.

In isolation, successfully performing $G$ entails only that one has the ability to $G$, not that one's performance was intelligent and not, therefore, that one knows how to G. According to Hawley (2003; see also Sosa, 2009), success per se is neither necessary nor sufficient for a claim to knowledge (that is, for knowing how to $\mathrm{G}$ qua knowledgein-action). Success is not sufficient if one succeeds only once, as is the case with the novice soldier who hits the bull's eye with his first ever shot (see also Carr's 1979 example of the novice dart player); but, importantly, neither is repeated success necessary: for it could be the case that I know how to G even if I do not succeed in Ging every time. After all, at the peak of his career, not even David Beckham succeeded in 'bending it like Beckham' on each occasion. ${ }^{10}$ For Hawley, what is necessary for knowledge how is not exhaustive success but, rather, reliable success. This is reflected in the precursor to knowledge-in-action: the Conditions for Intelligent Action (CIA).

(CIA) Where $w$ is a way of Ging, $\mathrm{S}$ must intend to perform $w$ (rather than 'other than $\left.w^{\prime}\right)$ and perform $w$ reliably as a way of intentionally Ging. ${ }^{11}$

\footnotetext{
${ }^{10}$ Hutto (2005) also notes that actions which exhibit knowledge how, in the form of a certain ability (or perhaps what might be thought of as a certain 'skill'), do not require this ability/skill to be infallible; rather, one must be able to engage in these actions reliably or competently (see also Jung \& Newen, 2010).

${ }^{11}$ An earlier version of the CIA can be found in Young (2011, p.62). See also Dickie (2012) for a similar approach to skilled action.
} 
In light of the CIA, consider the following personal entailments:

(a) S performing $\mathrm{G}$ under the CIA entails $\mathrm{S}$ has the ability to $\mathrm{G}$

(b) S performing $\mathrm{G}$ under the CIA entails $\mathrm{S}$ knows how to $\mathrm{G}$ (qua knowledge-in-action)

(c) Given (a) and (b), S knowing how to G (qua knowledge-in-action) entails S has the ability to $\mathrm{G}$

Pat is able to satisfy (a) and (b) with regard to skiing; Albert is not. The claim that Pat knows how to $G$ therefore follows from satisfying the CIA and from the entailments evident in (a) and (b). The counterfactual position holds as far as Albert's knowledge how is concerned. Assuming ability enabling conditions are met, Albert's not knowing how to ski and not having the ability to ski follow from his not satisfying the CIA and subsequently statements (a) and (b). Taking onboard the CIA and statements (a) and (b), what follows from this - statement (c) - I call the personal ability entailment $\left(\mathrm{AE}_{\mathrm{personal}}\right)$ :

$\mathrm{AE}_{\text {personal }}$ : $\mathrm{S}$ knowing how to $\mathrm{G}$ (qua knowledge-in-action) entails $\mathrm{S}$ has the ability to $\mathrm{G}$.

The manner in which Pat and Albert's knowledge of skiing is differentiated is compatible with the $\mathrm{AE}_{\text {personal. }}$. If we compare Pat and Albert's knowledge-in-action

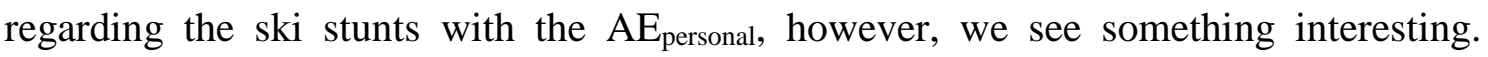


Albert's lack of ability and knowledge-in-action is compatible with the $\mathrm{AE}_{\text {personal }}$ but Pat's lack of ability is not. Put another way:

- The claim that Albert does not know how to G (perform the ski stunts) co-occurs with his not performing intelligent action $\mathrm{G}$ because he lacks the ability to $\mathrm{G}$

- The claim that Pat knows how to G (perform the ski stunts) co-occurs with his not performing intelligent action $\mathrm{G}$ because he lacks the ability to $\mathrm{G}$.

Given that both satisfy knowledge-about-how to G, whatever is differentiating Pat's knowledge how from Albert's (qua knowledge-in-action), it cannot be their ability to G (that is, perform the required intelligent action) - which, in this case, is the ski stunts since neither is able to do this. As things stand, it is not clear what forms the basis for Pat's additional knowledge over Albert's regarding the ski stunts, because, first, it is not based on performance and hence the ability to perform the stunts and, second, both Pat and Albert possess knowledge-about-how to G.

The key to resolving this issue is, I contend, the fact that Pat is able to satisfy the $\mathrm{AE}_{\text {personal }}$ with regard to skiing and Albert is not. To understand how this plays a part in differentiating Pat and Albert's knowledge regarding the ski stunts, we must distinguish between type and token actions, such that Pat's knowledge how to G (qua knowledgein-action) entails only that he has the ability to $\mathrm{G}_{\text {type }}$ and not necessarily the ability to 
$\mathrm{G}_{\mathrm{token}}$, whereas Albert does not have the ability to $\mathrm{G}_{\mathrm{type}}$ nor, because of this, the ability to $G_{\text {token. }}$.

\section{Distinguishing between type and token actions}

\subsection{Type and token actions 1}

To understand the difference between type and token actions, let us first be clear on how types and tokens per se are typically understood. Consider the following example: Pat and Albert receive the same book for their respective birthdays. What is meant by the same book here? It could be that for their birthday, Pat and Albert each receive a different copy of the same book, Cooking for Beginners. 'Cooking for Beginners' is a type of book, and the gift Pat receives - the specific copy - is a token of that book-type. In turn, Albert received a different copy and so a different token of the same book-type for his birthday. Alternatively, it could be that Pat gave Albert a copy of 'Cooking for Beginners' for his birthday and sometime later, on Pat's birthday, because he had forgotten who had originally given him the book and because he had never read it, Albert gave Pat the book back as a present. Here, on different occasions, both Albert and Pat receive the same token of the same type of book as a gift. It could also transpire that, for his birthday, Pat received the same book from five different friends: meaning he receives five tokens of the same type.

With this last example in mind, consider the following point made by Jung and Newen (2011) when discussing the question of individuating abilities. Jung and Newen 
(with reference to Snowdon, 2003) describe Martin, who is able to perform fifty consecutive sit-ups. They then go on to state:

We do not ascribe a specific knowing-how to Martin since the ability to do exactly fifty consecutive sit-ups is, in general, not of interest. We would rather credit Martin with the ability to do sit ups (and the corresponding knowing-how, respectively) and emphasize that he is able to perform it with an impressive strength and endurance. (2011, pp.82-3; emphasis in original)

In being able to perform fifty consecutive sit-ups, Martin is able to do more than Malcolm who is able to perform only thirty sit-ups consecutively. Alongside this difference in performance, do Martin and Malcolm differ in their knowledge how (as described by the $\mathrm{AE}_{\text {personal }}$ )? Is it that Martin knows how to $\mathrm{G}_{50}$ (where $\mathrm{G}=$ perform consecutive sit-ups) and Malcolm does not? According to Jung and Newen, individuating one's ability and even knowledge how to such a finite degree is of little general interest. Perhaps we need to reconsider this, however, at least as a means of arriving at a more interesting end.

It is my contention that Martin and Malcolm share an ability to perform a certain type of action $(\mathrm{G})$, and differ only with regard to individual tokens of that type of action, which is tied to their respective strength and agility. Each can perform sit-ups (a particular type of action), yet they differ in the number of tokens of this action they can perform consecutively (50 and 30, respectively). As such, each can be said to know how to $\mathrm{G}$ (qua knowledge-in-action), where $\mathrm{G}$ corresponds to a type of action, not a specific token of it. This is in keeping with the $\mathrm{AE}_{\text {personal. }}$ 
In the case of Malcolm, I would accept that knowing how to $\mathrm{G}_{50}$ can occur independently and therefore in the absence of the subject's corresponding ability to $\mathrm{G}_{50}$ only because $\mathrm{G}_{50}$ amounts to a series of token actions derived from a type of action that the subject is able to perform. I call this the Type-Token Action Clause (TAC) with regard to knowledge-in-action. More formally:

TAC: $S$ knows how to $G_{\text {token }}$ in the absence of the ability to $G_{\text {token }}$ iff $S$ is able to $G_{\text {type }}$

How might the TAC help resolve the seeming conflict between the $\mathrm{AE}_{\text {personal }}$ and the example of Pat and the ski stunts? To see how, we need to consider a further means of distinguishing between types and tokens.

\subsection{Type and token actions 2}

By way of a different example of types and tokens, consider the following representations: $\mathbf{t}, t, t, \mathbf{t}, t$. Each representation is a different token of the same type of letter, tee. In the book example, the different tokens (each copy) were identical to each other. Here, the physical characteristics of each token differ from each other by varying degrees, yet each is considered a token of the same letter-type. Even though the tokens differ physically, they retain a sufficient but indeterminate number of similar characteristics which are used to classify them as belonging to the same type; although 
the line between being and not being sufficiently similar may be nebulous and a matter of interpretation, context or even consensus. Does $\tau$ count as a token of the letter tee, for example?

In the earlier example involving sit-ups, each token sit-up was (roughly speaking) identical to the others; there was only a quantitative difference between $\mathrm{G}_{30}$ and $\mathrm{G}_{50}$. Now, while it may go without saying that performing ski stunts is a more complex activity than performing sit-ups, how does performing these stunts differ from skiing? Bengson and Moffett do not provide any details about what the ski stunts involve, other than saying that they are complex and, presumably, bear some relation to skiing: hence, ski stunts. What remains unclear, then, is whether the ski stunts constitute a series of token acts derived from acts that are categorized as belonging to a certain action-type - namely, skiing - or whether they should be thought of as tokens of a different action-type altogether. I will consider each in turn.

First, it may be that the ski stunts incorporate a number of regular ski moves tokens of the overall type of action we classify as skiing - only in a less orthodox sequence or at a heightened speed; something which Pat finds difficult (impossible, in fact) to execute, despite his more general ability to ski. Thus, in accordance with TAC, Pat knows how to $\mathrm{G}_{\text {token }}$ - that is, perform a series of regular ski moves in a novel way $\left(\mathrm{G}_{\text {token1}}, \mathrm{G}_{\mathrm{token} 2}, \mathrm{G}_{\mathrm{token} 3}\right.$, etc. $)$ - despite his inability to do so, because he has the ability to $\mathrm{G}_{\text {type }}$ (ski). The fact that he satisfies the $\mathrm{AE}_{\text {personal, }}$, meaning he has the ability to $\mathrm{G}_{\text {type }}$ (ski), bestows on him knowledge-in-action regarding all of the tokens mentioned. (This can be likened to the example of different tokens of the letter tee which share indeterminate but sufficient characteristics with the letter-type.) Pat's failure to execute the stunts reflects his inability to perform the moves at the required speed or in the 
required order, or has something to do with the terrain over which they are meant to take place (etc.). Albert, on the other hand, does not know how (qua knowledge-inaction) to $\mathrm{G}_{\text {token }}$ (perform the ski moves in a novel - stunt-like - way) because he does not have the ability to $G_{\text {type }}$ (ski) and so does not satisfy the $A E_{\text {personal with regard to }}$ skiing.

Alternatively, let us consider the possibility that the ski stunts constitute a different action-type altogether, rather than being mere tokens of the action-type 'skiing'. If so, then what is less clear from Bengson and Moffett's vignette is how Pat could know how to perform the ski stunts under such conditions. It needs to be stipulated how the ski stunts relate to the ability Pat has to ski, such that he is able to 'grasp' how to do them through his ability to ski (which is the means of distinguishing Pat from Albert). Depending on the distal/proximal relationship of the stunts to skiing, would someone who is able to water ski be able to grasp them also in a way that Albert could not? What about an expert roller-blader? Clearly, what makes it more intuitively the case that Pat knows how to perform the ski stunts (his 'grasp' of how to do them) is the fact that he already possesses the ability (and with it the know-how qua knowledgein-action) to ski.

It may be objected that the type-token relationship described in the example of sit-ups - which was used to distinguish Malcolm from Martin - is purely quantitative and differs somewhat from the relationship suggested between the token ski stunts and the action-type 'skiing'. This is true. The latter example, as mentioned above, is more akin to the letter tee example in which what counts as a token of this letter-type may well be open to interpretation, context and consensus. What counts as an act of skiing is equally reliant on these things. In my defence, however, I am not trying to present types 
or tokens as absolutes. Moreover, I do not consider this issue to be unique to the taxonomy of action, and hold that the same problem can be found when trying to categorize other objects or events; but this does not negate the usefulness of drawing distinctions in these cases. ${ }^{12}$ What should concern us, then, is not whether it is conceptually coherent to categorize a ski stunt as a token example of a larger ski-type (I accept a certain level of conceptual fuzziness, as far as this is concerned) - but, rather, the extent to which one's level of personal ability (to ski, in this case), inherent within the CIA (the precursor to the knowledge-in-action described by the $\mathrm{AE}_{\text {personal }}$ ), is (A) prerequisite to performing the ski stunts and (B) that from which the ability to perform the ski stunts is derived. Should (A) and (B) be accepted, then the TAC provides a useful heuristic for understanding the relationship between knowledge how (qua knowledge-in-action) and ability.

In concluding this section, I agree with Bengson and Moffett that Pat and others like him who lack the ability to $\mathrm{G}$ can still possess knowledge-in-action regarding $\mathrm{G}$. However, to make this accord compatible with the $\mathrm{AE}_{\text {personal, }}$ one must accept that what Pat lacks is the ability to perform $\mathrm{G}_{\text {token(s) }}$ (where a $\mathrm{G}_{\text {token }}$ equates to a ski stunt, in this case), not the ability to $\mathrm{G}_{\text {type }}$ (where $\mathrm{G}_{\text {type }}$ equates to skiing).

\section{Knowledge-in-action and performing the impossible}

Let us apply the TAC to the earlier example of Irina and the other world class figure skaters. If we allow (as seems reasonable) that all these skaters know how to $\mathrm{G}$ (qua knowledge-in-action) - where $\mathrm{G}$ equates to intelligently performing a salchow (under

\footnotetext{
${ }^{12}$ Borrowing from Wittgenstein, one might try to think of all the possible tokens of the type "game" and see if consensus can be achieved.
} 
the terms of the CIA) - and therefore allow that all satisfy the $\mathrm{AE}_{\text {personal }}$ in this regard, then they also know (qua knowledge-in-action) how to perform a quintuple salchow, as well as sextuple, septuple and octuple salchows, respectively. Their knowledge-inaction would seem, mutatis mutandis, to be on par with Malcolm's, who can perform thirty consecutive sit-ups but not fifty. ${ }^{13}$ Irina's ability to do some things but not others relates to a difference in the token action she is able to perform (a quadruple rather than a quintuple salchow), not the type of action (a salchow). Therefore, in accordance with the $\mathrm{TAC}$ and the $A E_{\text {personal, }}$ given her ability to $\mathrm{G}_{\mathrm{type}}$, there is no discrepancy between her knowledge-in-action to $\mathrm{G}_{\text {token4} 4}$, where $\mathrm{G}_{\text {token4 }}$ relates to a quadruple salchow, and her

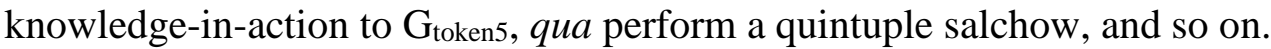

As with knowledge-about-how, discussed in Section 2, these latter examples of salchows leave the TAC vulnerable to the charge of permitting knowledge-in-action about an action-token (in virtue of the performability of the action-type from which the token is derived) that is potentially impossible to perform. A commitment to the TAC and the $\mathrm{AE}_{\text {personal }}$ requires that we endorse the claim that Malcolm knows how to perform fifty consecutive sit-ups, despite being unable to perform this token action: a position that seems reasonable. Somewhat counter-intuitively, perhaps, by the same reckoning, Irina knows how to $\mathrm{G}_{\text {token(c) }}$ (perform a chilialchow) in the absence of the ability to $G_{\text {token(c) }}$ because she has the ability to $G_{\text {type }}$ (perform a salchow). As it stands, the $\mathrm{TAC}$ and the $\mathrm{AE}_{\text {personal }}$ enable knowledge how to $\mathrm{G}_{\text {token }}$ (qua knowledge-in-action) to be granted, not only in the absence of an ability to perform the $\mathrm{G}_{\mathrm{token}}$, but in the absence of any requirement to comply with what is possible to perform and therefore what is

\footnotetext{
${ }^{13}$ Similar to a point made earlier (see footnote 8), it may be that these salchows require drastic changes to how one approaches the manoeuvre. As such, the change to the action may involves more than increasing the rotations through the air and so may be less akin to the sit-ups example than suggested here.
} 
possible to have the ability to perform. As such, the TAC and the $\mathrm{AE}_{\text {personal }}$ force us to conclude that Irina knows how to perform the somewhat lavish chilialchow. However, in keeping with the need to restrict knowledge how to possible action (as stipulated by the $\mathrm{AE}_{\text {abstracted}}$ ), let us consider an amended version of the TAC: the Possible TypeToken Action Clause (PTAC).

PTAC: $S$ knows how to $G_{\text {token }}$ in the absence of the ability to $G_{\text {token }}$ iff $S$ is able to $G_{\text {type }}$, and $\mathrm{G}_{\mathrm{token}}$ is possible to perform.

The addition of the clause "and $\mathrm{G}_{\text {token }}$ is possible to perform" means that the PTAC is

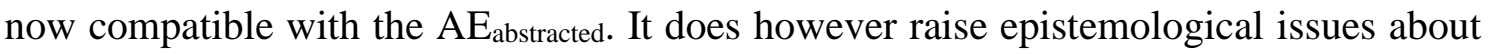
how one might establish this possibility. In the absence of an actual performance, one might argue with some justification that the clause is really stating "and $\mathrm{G}_{\text {token }}$ is considered possible to perform" (or is not considered, or has not been shown to be, impossible to perform). Certainly, in the absence of evidence, the line between what is considered possible and impossible is rather fuzzy and empirically unsubstantiated. ${ }^{14}$

Given my contention that knowing how to $\mathrm{G}_{\text {token }}$ (qua knowledge-in-action) entails the ability to $\mathrm{G}_{\mathrm{type}}$, perhaps we can deduce ( a priori) our possible action-tokens from the a posteriori knowledge we possess: say, based on our knowledge of human physiology, and existing demonstrations of other action-tokens which are derived from a performable action-type, such as the current maximum number of rotation through the air a human figure skater can perform and the fact that this number is way below the one thousand required for the chilialchow. From this, it is evident that one should

\footnotetext{
${ }^{14}$ Simpson (2010) refers to examples of knowledge how (potentially) in the absence of ability - similar to some of the examples used here - as having conceptually clear but empirically vague boundaries.
} 
conclude that it is impossible for a human to rotate a thousand times through the air unaided. But what about something that has not yet been achieved: say, the sextuple salchow?

Imagine there is a consensus among the world's best figure skaters that it is not impossible to perform a sextuple salchow (although they remain silent on how they arrived at this conclusion). Do all the world's best figure skaters know how to perform this particular move (qua knowledge-in-action)? ${ }^{15}$ In the absence of a posteriori verification that it can be achieved and therefore that we have the ability to perform this particular $\mathrm{G}_{\text {token }}$ - should it rightly be called knowledge how? In such circumstances, and with reference to such an act, when referring to knowledge-about-how, at best one can only hypothesize how to perform this version $\left(\mathrm{G}_{\text {token }}\right)$ of the salchow. This hypothesis will either be supported when a performance finally occurs (contributing to the hypothesis' transformation into knowledge-about-how) or remain a hypothesis until an alternative means of performing the manoeuvre either refutes the hypothesis itself or removes any practical need for continuing with it, given that an alternative way to $\mathrm{G}$ has been established. When referring to knowledge-in-action, on the other hand, perhaps one needs to bite the bullet (so to speak) and accept that, where the performability of a token action is uncertain, one should not declare that ' $S$ knows how to $G_{\text {token }}$ ' in accordance with PTAC and its forerunner the $\mathrm{AE}_{\text {abstracted. }}$

In light of this claim, consider the fact that at the time of writing the worldrecord for the number of sit-ups was 133, 986 (set in 30 hours). The record holder, Edmar Freitas, in setting this record, surpassed his own previous world record $(111,000$

\footnotetext{
${ }^{15}$ Of course, one cannot draw an ontological conclusion from an epistemic premise. It is therefore invalid to reason as follows: we believe it is possible to perform a sextuple salchow therefore it is possible to perform a sextuple salchow. Such a fact does not undermine the PTAC per se; rather, it undermines its practical application in certain cases.
} 
sit-ups). During his attempt at the record, I would argue that Edmar knew how to $\mathrm{G}_{\text {token }}$ (perform 133,986 sit-ups) and knew how even if he had failed to achieve this number and, equally, he knows how to perform 133,987 sit ups, now, even though he has never achieved this number and even if he never does: for, based on what we do know about human physiology, there is no good reason to think that such a number is impossible to achieve, unlike the case of the chilialchow.

Stating that there is no good reason to hold that we do not have the ability to $\mathrm{G}_{\text {token }}$ reminds us of the fact that the line between possible and impossible token action is nebulous. How one establishes the existence of the ability to $\mathrm{G}_{\text {token }}$ in the absence of demonstrable validation (i.e., performance), and therefore how one moves between knowledge-about-how and what is in effect a hypothesis, or possessing knowledge-inaction and not possessing it, is of course a separate epistemic matter. This issue is not something which need undermine the $\mathrm{AE}_{\text {abstracted }}$ or $\mathrm{AE}_{\text {personal }}$ (basically, the fact that knowledge how - in either form - entails ability). Instead, it highlights the difficulty we have establishing a legitimate claim to knowledge how given knowledge how's dependence on performability, and so ability. Accepting this, but in recognition of the PTAC (and therefore the $\mathrm{AE}_{\mathrm{abstracte}}$ ), the following amendment is required to the $\mathrm{AE}_{\text {personal: }}$

*AE $\mathrm{E}_{\text {personal }}$ : Where $\mathrm{G}_{\text {token }}$ is possible, $\mathrm{S}$ knowing how to $\mathrm{G}_{\text {token }}$ (qua knowledge-in-action) entails $S$ has the ability to $G_{\text {type }}$

\section{Conclusion}


The main aim of this paper has been to examine the nature of the entailment between knowledge how and ability. What I hope to have shown is that in addition to the need for an abstracted ability to $\mathrm{G}$, as a prerequisite for any form of knowledge how, where knowledge how equates to knowledge-in-action, a personal ability entailment exists. What it means to have the personal ability to $G$, as a necessary condition for knowledge-in-action, however, needed to be qualified. In doing this, I distinguished between type and token abilities, such that for $\mathrm{S}$ to know how to $\mathrm{G}$ it is necessary for $\mathrm{S}$ to have the ability to $G_{\text {type }}$ but not necessarily $G_{\text {token. }}$. Such a distinction, I contend, offers a way of reconciling the intellectualist and anti-intellectualist positions regarding knowledge how and its relation to ability.

Acknowledgments: I would like to thanks the anonymous reviewers for their insightful and constructive comments. 


\section{References}

Bengson, J., \& Moffett, M. A. (2007). Know-how and concept possession. Philosophical Studies, 136, 31-57.

Bengson, J., \& Moffett, M. A. (2012). Nonpropositional Intellectualism. In J. Bengson, \& M. A. Moffett (Eds.). Knowing How: Essays on Knowledge, Mind, and Action (pp.161-195). Oxford: Oxford University Press.

Carr, D. (1979). The logic of knowing how and ability. Mind, 88(351), 394-409.

Devitt, M. (2011). Methodology and the Nature of Knowing How. Journal of Philosophy, CVIII, 205-218.

Dickie, I. (2012). Skill Before Knowledge. Philosophical and Phenomenological Research, 85(3), 737-745.

Fantl, J. (2008). Knowing-How and Knowing-That. Philosophical Compass, 3(3), 451470. 
Fridland, E. (2013). Problems with Intellectualism. Philosophical Studies, 165, 879891.

Hawley, K. (2003). Success and Knowledge How. American Philosophical Quarterly, 40(1), 19-31.

Hutto, D.D (2005). Knowing what? Radical versus conservative enactivism. Phenomenology and the Cognitive Sciences, 4, 389-405.

Jung, E-M., \& Newen, A. (2010). Knowledge and abilities: The need for a new understanding of knowing how. Phenomenology and the Cognitive Sciences, 9(1), 113131.

Jung, E-M., \& Newen, A. (2011). Understanding Knowledge in a New Framework: Against Intellectualism as a Semantic Analysis and an Analysis of the Mind. In A. Newen, A. Bartels, \& E-M. Jung (Eds.) Knowledge and Representation (pp.79-105). Palo Alto: CSLI Publications and Paderborn: Mentis Verlag.

Millikan, R.G. (2000). On Clear and Confused Ideas: An Essay About Substance Concepts. Cambridge. Cambridge University Press. 
Noë, A. (2005). Against Intellectualism. Analysis, 65(4), 278-290.

Ryle, G. (1949). The Concept of Mind. London: Hutchinson.

Snowdon, P. (2003). Knowing How and Knowing That: A Distinction Reconsidered. Proceedings of the Aristotealian Society, 105(1), 1-25.

Sosa, E. (2009). Reflective Knowledge: Apt Belief and Reflective Knowledge. Oxford: Oxford University Press.

Simpson, D. (2010). Language and know-how. Phenomenology and the Cognitive Sciences, 9, 629-643.

Stanley, J., \& Williamson, T. (2001). Knowing How. Journal of Philosophy, 98(8), 4113444.

Young, G. (2011). Irreducible forms of knowledge how in patients with visuomotor pathologies: An argument against intellectualism. In: A. Newen, A. Bartels, \& E.-M. Jung (Rds.), Knowledge and Representation (pp31-57). Palo Alto: CSLI Publications. 